\title{
CHROMOSOMAL LOCATION AND EVOLUTION OF ISOZYME STRUCTURAL GENES IN HEXAPLOID WHEAT
}

\author{
GARY E. HART and PAT J. LANGSTON \\ Genetics Section, Department of Plant Sciences, Texas A \& M University, \\ College Station, Texas 77843, U.S.A.
}

Received 16.xii.76

\section{Summary}

The genetic control of the production of multiple forms of lipoxygenase, endopeptidase, acid phosphatase, aminopeptidase, and alcohol dehydrogenase in hexaploid wheat has been studied using the zymogram technique. Aneuploid strains which encompass a range of from zero to four doses of each chromosome in the complement were analysed. The localisation of 22 structural genes to specific chromosorne arms is reported. Extensive intergenomic variation between homoeologous isozyme structural genes has been detected. The results of this study are consistent with the hypothesis that many of the duplicated structural genes of this species have diverged in structure and function subsequent to the origin of the polyploid wheats.

\section{INTRODUCTION}

Duplicated genetic material has long been considered to be an important source of raw material for evolution in polyploid (Haldane, 1932, 1933; Harland, 1934, 1936) as well as in diploid species. However, although cytogenetic and genetic studies have established that the possession of an extensive quantity of duplicated genetic material is a characteristic and significant feature of polyploid species, a generalised understanding of the evolutionary fate and the functional role of duplicate structural genes in polyploids has not yet been derived.

An assessment of the nature and the extent of inter-genomic structural gene variation that is present in hexaploid wheat ( $\mathcal{T}$. aestivum L., $2 n=42$, genomes A, B, and D) may be made by analysing appropriate aneuploid strains with the zymogram technique. Furthermore, since the tetraploid and two of the three diploid species which contributed genomes to the species are known and extant (McFadden and Sears, 1946; Riley, 1965), comparative studies may allow the probable allelic composition of duplicate structural gene loci that were contained in the newly-formed polyploid to be ascertained and the nature and the extent of evolutionary change which has occurred in structural genes subsequent to the origin of the species to be determined.

This paper reports the results of analyses of the inter-genomic variation present in hexaploid wheat in structural genes for endopeptidase, lipoxygenase, aminopeptidase, acid phosphatase, and alcohol dehydrogenase. The principal findings reported are the localisations of 22 structural genes to specific chromosome arms. The results of this study, which demonstrate 
cxtensive inter-genomic variation in isozyme structural genes, are not in agreement with the suggestion of Sing and Brcwer (1969) and Brcwer et al. (1969) that sclection for identical gene content in the three genomes of hexaploid wheat has resulted in a convergence in the genetic content of the three genomes. A brief account of some of this research was reported in a symposium paper (Hart, 1973).

\section{Materials AND methods}

The 21 chromosomes of hexaploid wheat belong to seven homoeologous groups. Each group is composcd of three chromosomes-one cach from the three genomes of the species-which exhibit a high degree of functional identity (Sears, 1954, 1966a). This functional identity, a consequence of extensive duplication and triplication of genetic material, has allowed the construction of a large number of aneuploid strains of diverse chromosmal constitution.

Each of the structural gene localisations reported in this paper is based on the demonstration that the level of expression of a specific gene product, as observed with the zymogram technique, varies concordantly with the dosage of a specific chromosome (and, in most cases, of a specific arm of that chromosome) but is unaffected by variation in the dosage of cach of the other chromosomes in the complement. The aneuploid strains which have been derived in the cultivar " Chinese Spring " by Sears (1954, 1966a, 1966b) encompass a range of from zero to four doses of each chromosome and of most chromosome arms. In practice, thc procedure has been to use the available compensating nullisomic-tetrasomic strains (which allow an examination of the phenotypic effects of zero, two, and four doses of each chromosome, except for zero doses of 2A) to localise the structural genes for a particular enzyme system to the chromosomes of a homoeologous group and then to use the available ditelosomic strains of that group to further localise the genes in specific chromosome arms.

There are 42 possible compensating nullisomic-tctrasomic combinations, six for each of the seven homoeologous groups. All of these types, with three exceptions (nulli-2A tetra-2B, 2A-2D, and 4A-4D, which are sterile or nearly so) have been analysed. Ditelosomic $2 \mathrm{AS}$ and monotelo-2AS ditelo2AL strains (the formcr are deficient for the long arm of chromosome 2A and the latter possess only onc dose of the short arm of 2A) were analysed to determine the possible effect of a reduction in the dosage of chromosome 2A. Other aneuploid types used in the analysis of one or more enzymes included the following.

Alcohol dehydrogenase (ADH), acid phosphatase (ACPH), and lipoxygenase (LPX) : nulli-4A, mono-4A tetra-4B, monoisosomic- $4 \mathrm{~A} \alpha$, each of the possible ditelosomic typcs of group 4, except ditelo-4A $\beta$ and ditelo-4BS, and, for LPX only, ditelo-5AL, ditelo-5BL, and ditelo-5DL.

Aminopeptidasc (AMP) : each of the possible ditclosomic types of group 6, cxcept ditelo-6AL, and mono-4A tetra-4B.

Endopcptidase (EP): cach of the possible ditelosomic types of the 7 group, except ditelo-7DL.

Extracts of mature whole grains or of the embryos of mature grains were used for the $\mathrm{ADH}$ analyses. For the $\mathrm{ACPH}, \mathrm{AMP}$, and $\mathrm{EP}$ analyses, 
extracts of shoots of 7-day-old etiolated seedlings grown in moist paper towelling at $23^{\circ} \mathrm{C}$ were used. Extracts of coleoptiles from 4-day-old green seedlings grown in moist paper towelling at $23^{\circ} \mathrm{C}$ in a growth chamber with a 12-hour day were used for the LPX studies. Extracts were obtained by maceration of tissue with sand in a mortar with pestle in a $p \mathrm{H} 7.5$ buffer containing $0 \cdot 1 \mathrm{M}$ tris(hydroxymethyl) aminomethane- $\mathrm{HCl}, 0 \cdot 1 \mathrm{M} \mathrm{KCl}, 0 \cdot 005 \mathrm{M}$ EDTA, and 0.04M 2-mercaptoethanol (Carlson, 1972). For LPX analyses, the buffer also contained $0 \cdot 05 \mathrm{~m}$ sucrose. A weight : volume ratio of tissue : buffer of 1 : 5 was used for mature kernels and of $1: 20$ for embryos for $\mathrm{ADH}$, of $1: 2$ for shoots for AMP and ACPH, of $1: 5$ for shoots for EP, and of $1: 10$ for coleoptiles for LPX.

The slurry obtained by maceration was centrifuged at $30,000 \times g$ for 15 minutes. The supernatant obtained was used directly for electrophoresis. Extraction and centrifugation were carried out at $2-5^{\circ} \mathrm{C}$. The zymogram phenotype of each enzyme was determined for from 3 to 10 grains (ADH) or plants of each aneuploid type.

Extracts were electrophoresed for the determination of the $\mathrm{ADH}, \mathrm{ACPH}$, AMP, and EP zymogram phenotypes in vertical starch gels (Electrostarch, 11 per cent, w/v), using methods previously described (Hart, 1973). Gels were stained for ADH as described by Hart (1970). Prior to staining for AMP, EP, and ACPH, gels were soaked for $1 \frac{1}{2}$ hours at $2-5^{\circ} \mathrm{C}$ in several changes of stain buffer. AMP and EP were stained at $37^{\circ} \mathrm{C}$ in $0 \cdot 1 \mathrm{M}$ trismaleate, titrated to $p \mathrm{H} 5.8$ with $\mathrm{NaOH}$, and $\mathrm{ACPH}$ at room temperature in $0 \cdot 1 \mathrm{M}$ acetate, $p \mathrm{H} \mathrm{5} \cdot 0$, as described previously (Hart, 1973; Tang and Hart, 1975).

The LPX zymogram phenotypes were determined using disc acrylamide gel electrophoresis procedures described by Hart (1975). The $6.5 \mathrm{~cm}$-long separation gel was made to 0.5 per cent Electrostarch. The starch was completely dissolved in $\mathrm{H}_{2} \mathrm{O}$ by heating and stirring and this solution allowed to cool to room temperature before being combined with the other reagents. The LPX staining procedure used was modified from that of Guss et al. (1968). A stock substrate solution was prepared by dispersing $0.5 \mathrm{~g}$ of linoleic acid in $25 \mathrm{ml}$ of freshly deionised $\mathrm{H}_{2} \mathrm{O}$ with the aid of a drop of Tween 80 and sonication under a stream of nitrogen. The total volume was then made to $50 \mathrm{ml}$ with $\mathrm{H}_{2} \mathrm{O}$. This stock solution was made fresh weekly and was stored at $2-5^{\circ} \mathrm{C}$ in the dark under nitrogen. After electrophoresis, each gel was incubated for 30 minutes at room temperature in about $7 \mathrm{ml}$ of a freshly prepared 20 -fold dilution of the stock substrate solution in $0.05 \mathrm{M}$

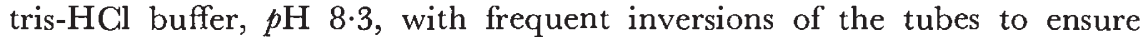
aeration. During the period of incubation of the gels with substrate, a KI incubation mixture was prepared. $100 \mathrm{ml}$ of 15 per cent acetic acid was purged with nitrogen and then, also under nitrogen, mixed with $5 \mathrm{ml}$ of a saturated solution of $\mathrm{KI}$ in $\mathrm{H}_{2} \mathrm{O}$. After completion of the 30-minute substrate incubation, the gels and gel containers were briefly rinsed in $\mathrm{H}_{2} \mathrm{O}$ and then each gel container was completely filled with the KI incubation mixture, stoppered, and incubated at room temperature. Zones of LPX activity became visible as brown bands on the gels in about 5 minutes and reached maximum intensity and resolution in 15 to 20 minutes. The LPX bands fade rapidly thereafter so photographs or drawings were made immediately of all gels for which a record of the zymogram phenotype was desired. 


\section{Results}

\section{(i) Alcohol dehydrogenase}

An earlier analysis of the ADH zymogram phenotypes of 38 of the "Chinese Spring" compensating nulli-tetra types and of a monoiso-4A $\alpha$ strain demonstrated that the ADH structural genes of hexaploid wheat are located in the chromosomes of homoeologous group 4 (Hart, 1970). The results of this study were in full accord with the proposal that the group 4 homoeologues each possess an $\mathrm{ADH}$ structural gene, that the three structural genes each encode approximately the same quantity of subunit, that the active $\mathrm{ADH}$ isozymes are dimers produced by the random association of subunits, and that each of the dimeric types produced is equally active. The chromosome 4A, 4B, and 4D ADH structural genes have been designated $A d h-A 1$ (formerly designated $\left.A d h_{A}\right), A d h-B 1\left(A d h_{B}\right)$, and $A d h-D 1\left(A d h_{D}\right)$, respectively, and the protomers which they encode $\alpha, \beta$, and $\delta$, respectively. The three ADH isozymes of hexaploid wheat are designated ADH-1 ( $\alpha \alpha$ dimers), $\mathrm{ADH}-2(\alpha \beta$ and $\alpha \delta)$, and $\mathrm{ADH}-3(\beta \beta, \delta \delta$, and $\beta \delta)$. These isozymes occur, respectively, at the sites of bands 1,2 and 3 in $\mathrm{ADH}$ zymograms (see fig. 1).

The chromosome arm location of $A d h-A 1$ has been determined by analysing nulli-4A tetra-4B, ditelo- $4 \mathrm{~A} \alpha$, monoiso-4A $\alpha$ and nulli-4A grains. In the absence of $A d h-A 1, \mathrm{ADH}-1$ and $\mathrm{ADH}-2$ are not expected to be produced, for $\alpha$, the protomer encoded by this gene, is a necessary component of both of these isozymes. It was found that ditelo- $4 \mathrm{~A} \alpha$ and monoiso-4A $\alpha$ grains produce a zymogram phenotype indistinguishable from that of "Chinese Spring" while nulli-4A tetra-4B and nulli-4A grains express only $\mathrm{ADH}-3$. These findings indicate that $A d h-A l$ is located in $4 \mathrm{~A} \alpha$. (The earlier erroneous linkage of $A d h-A 1$ to $4 \mathrm{~A} \beta$ (Hart, 1970) was based on the absence of expression of ADH-1 and ADH-2 in grains which were assumed to be monoisosomic for $4 \mathrm{~A} \alpha$ but which were actually nullisomic for $4 \mathrm{~A}$.)

With two doses of each ADH structural gene present, the expected quantitative distribution of $\mathrm{ADH}-1, \mathrm{ADH}-2$, and $\mathrm{ADH}-3$ is $1: 4: 4$, respectively. However, in the absence of either $A d h-B 1$ or $A d h-D 1$, given two doses of the other two ADH structural genes, the distribution is expected to be $1: 2: 1$, a distribution which is produced by most strains of $T$. turgidum $(2 n=28$, genomes $\mathrm{A}$ and $\mathrm{B})$, including PI 226951 (A, fig. 1). The relative staining intensities of the three bands which compose the ditelo-4DL phenotype approximate a $1: 2: 1$ ratio (B, fig. 1) while ditelo4DS grains produce a phenotype indistinguishable from that of "Chinese Spring ". These findings link $A d h-D 1$ to $4 \mathrm{DS}$. Ditelo-4BL grains express the "Chinesc Spring" ADH phenotype, indicating that $A d h-B 1$ is located in 4BL. Ditelo-4BS grains arc not available.

\section{(ii) Aminopeptidase}

Diagrams of some of the AMP zymogram phenotypes observed in this study are shown in fig. 3. A photograph of a starch gel zymogram which displays these phenotypes has been published (Hart, 1973).

Euploid "Chinese Spring", each of the aneuploid strains examined that is disomic for each of the chromosomes of homoeologous group 6, and the 
ditelo-6AS (formerly designated 6A $\alpha$ ), ditelo-6BS, and ditelo-6DS $(6 \mathrm{D} \alpha$ ) strains produce phenotype I (fig. 3). Band 1 is not produced by strains nullisomic for chromosome $6 \mathrm{~A}$ (II and III, fig. 3), band 2 by strains nullisomic for $6 \mathrm{D}$ (VI and VII, fig. 3), and band 3 by strains nullisomic for $6 \mathrm{~B}$ (IV and V, fig. 3). Tetrasomy for each of these chromosomes causes an increase in the relative staining intensity of these respective bands (see also fig. 3). The absence of $6 \mathrm{DS}$ results in the absence of band 2 and of $6 \mathrm{BS}$ in the absence of band 3 .

These results provide strong evidence for the proposal that the chromosome arms 6AS, 6BS, and 6DS each possess a gene which encodes an AMP isozyme. The structural genes are designated $A m p-A 1, A m p-B 1$, and $A m p-D 1$,

\begin{tabular}{|c|c|c|c|c|c|c|c|c|}
\hline Phenotype & I & II & III & IV & V & VI & VII & \\
\hline Band Number & & & & & & & & Aminopeptidase \\
\hline 1 & 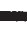 & & & & - & & & 1 \\
\hline 2 & & & & & & & & 2 \\
\hline 3 & & & & & & & & 3 \\
\hline \multicolumn{9}{|l|}{ Dosage of } \\
\hline $\begin{array}{l}6 \mathrm{~A} \\
6 \mathrm{~B} \\
6 \mathrm{D}\end{array}$ & $\begin{array}{l}2 \\
2 \\
2\end{array}$ & $\begin{array}{l}0 \\
4 \\
2\end{array}$ & $\begin{array}{l}0 \\
2 \\
4\end{array}$ & $\begin{array}{l}4 \\
0 \\
2\end{array}$ & $\begin{array}{l}2 \\
0 \\
4\end{array}$ & $\begin{array}{l}4 \\
2 \\
0\end{array}$ & $\begin{array}{l}2 \\
4 \\
0\end{array}$ & \\
\hline
\end{tabular}

FIG. 3.-Diagram showing the relationships between dosages of the group 6 chromosomes and the AMP zymogram phenotypes produced.

respectively, and the isozymes which they encode as AMP-1 (located at the site of band 1), AMP-3 (band 3), and AMP-2 (band 2), respectively. The gene symbols assigned are those appropriate for a homoeologous set of genes (McIntosh, 1973).

MacDonald and Smith (1972) observed the absence on strain ditelo-6BL zymograms of a cathodal aminopeptidase that was produced by euploid "Chinese Spring". It is probable that this aminopeptidase is the one designated here as AMP-3 and thus that they were observing on the ditelo$6 \mathrm{BL}$ zymograms the effect of the absence of $A m p-B 1$ from this strain.

\section{(iii) Acid phosphatase}

Six bands of ACPH activity have been resolved on starch gel zymograms in which extracts of shoots of 7-day-old etiolated seedlings of euploid "Chinese Spring" have been electrophoresed. Analyses of various aneuploid strains have shown that these bands are the products of a minimum of nine isozymes, three of which display low activity on zymograms.

A zymogram phenotype indistinguishable from that of euploid " Chinese Spring " is produced by each of the aneuploid strains that has been examined which is disomic for each of the chromosomes of homoeologous group 4 . However, each of the strains examined which is aneuploid for one or more group 4 chromosomes or chromosome arms (excepting the ditelo-4DL strain) produces an ACPH phenotype which differs from that produced by euploid 
"Chinese Spring". A photograph of some of the ACPH zymogram phenotypes observed is shown in fig. 2. Diagrams which show the relationships between dosages of the group 4 chromosomes and the ACPH zymogram phenotypes produced are shown in fig. 4. The zymogram locations of the ACPH isozymes are indicatcd by Arabic numerals shown on the right side of fig. 4.

The zymogram expression of six of the isozymes, namely ACPH-2, -3, $-4,-5,-6$, and -8 , varies concordantly with the dosage of specific group 4 chromosomes and chromosome arms. For examplc, ACPH-2 is not expressed in strains which lack either chromosome $4 \mathrm{~B}$ (IV and V, figures 2 and 4 ) or the short arm of chromosome $4 \mathrm{~B}$ while the relative staining

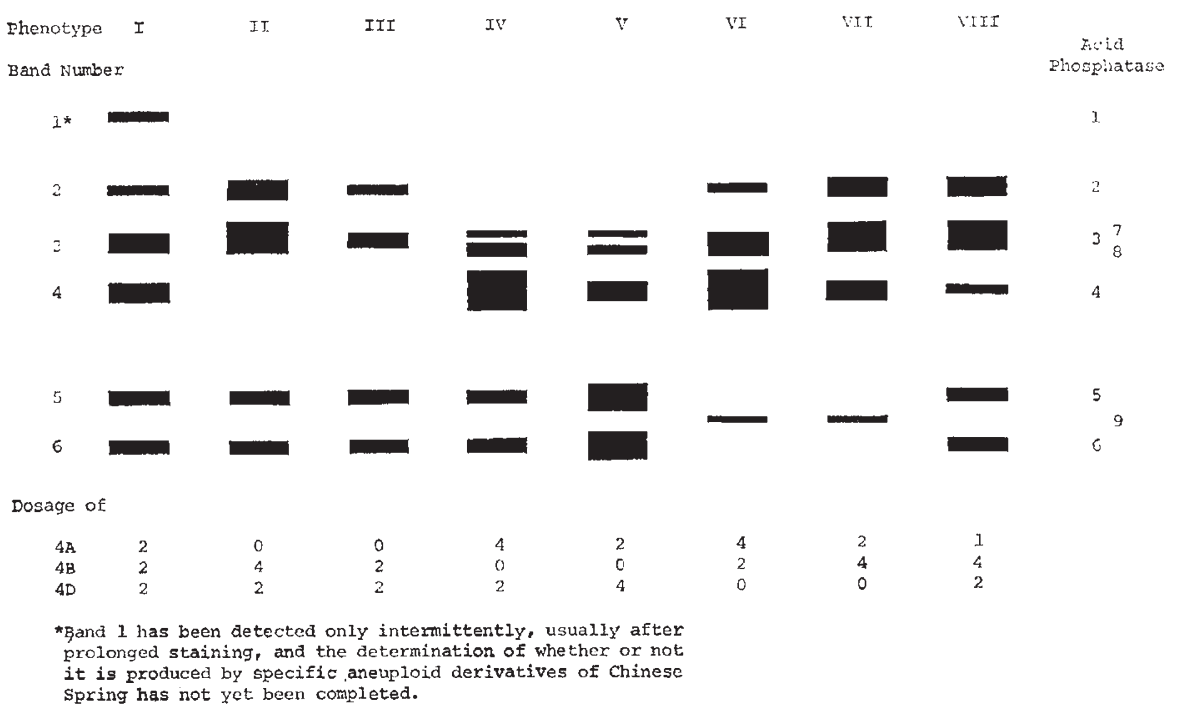

Fig. 4.-Diagram showing the relationships between dosages of the group 4 chromosomes and the ACPH zymogram phenotypes produced.

intensity of band 2 (the site of $\mathrm{ACPH}-2$ ) is increased when $4 \mathrm{~B}$ is tetrasomic (II, VII, and VIII, fig. 4; see also fig. 2). Likewise, ACPH-4 is not expressed in strains which lack either chromosome 4A (II and III, fig. 4) or the $\beta$ arm of chromosome $4 \mathrm{~A}$, whilc the relative staining intensity of band 4 (the site of ACPH-4) is increased with tetrasomy for chromosome 4A (IV and VI, figs. 2 and 4) and decreased with monosomy for 4A (VIII, fig. 4). The results indicate that each of these six isozymes is encoded by a structural gcne located in chromosome group 4. Specifically, the results indicate that ACPH- 4 and -8 are encoded by $4 \mathrm{~A} \beta$ structural genes, ACPH-2 and -3 by $4 \mathrm{BS}$ genes, and ACPH- 5 and -6 by $4 \mathrm{DL}$ genes.

The chromosome arms $4 \mathrm{~A} \alpha, 4 \mathrm{BL}$, and $4 \mathrm{DS}$ have been shown to carry a triplicate set of homoeologous $\mathrm{ADH}$ structural genes. Evidence will be presented below that a triplicate set of homoeologous LPX structural genes is located in the same arms. These results demonstrate that these three arms are at least partly homoeologous and they suggest that $4 \mathrm{~A} \beta, 4 \mathrm{BS}$, and $4 \mathrm{DL}$ are also at least partly homoeologous with each other and thus that the ACPH genes are homoeologous. The results of a study of the developmental 
and tissue specificities and of the molecular weights of Triticum ACPH's are in agreement with this suggestion (Torres and Hart, 1976). While it thus seems probable that the ACPH structural genes which have been identified are genetically related by descent from one or more primordial genes, no specific homoeologous relationships have thus far been established. Consequently, we designate the structural genes by conventional symbols, rather than those which are to be applied to homoeologous sets (McIntosh, 1973). The structural genes for ACPH-2 and -3, located in 4BS, are designated $A c p h 2$ and $A c p h 3$, respectively, for ACPH-4 and -8, located in $4 \mathrm{~A} \beta, A c p h 4$ and $A c p h 8$, respectively, and for ACPH-5 and -6, located in 4DL, Acph5 and Acph6, respectively.

ACPH-7 and ACPH-9 both display low activity on zymograms (fig. 4). The former has an electrophoretic mobility which partially overlaps that of ACPH-3 and can be resolved only when ACPH-3 is not expressed. ACPH-9 has an electrophoretic mobility intermediate to that of ACPH-5 and -6 and can be resolved only when these isozymes are not expressed. The manner of chromosomal control of ACPH-7 and ACPH-9 and also of ACPH-1, which has been detected only intermittently after prolonged staining, has not been determined. Other materials and/or methods will need to be employed to obtain evidence for the chromosomal location of the structural genes which encode these isozymes.

\section{(iv) Endopeptidase}

Diagrams of some of the EP zymogram phenotypes observed are shown in fig. 5. Each of the six group 7 nulli-tetra types and each of the three group 7 short arm ditelo strains produces a distinctive EP zymogram phenotype. However, euploid "Chinese Spring" plus the aneuploid strains examined that are disomic for the chromosomes of group 7 plus, in addition, two ditelosomic strains, ditelo-7AL and ditelo-7BL, produce the same phenotype, phenotype I.

The pattern of variation observed suggests that the band of intermediate electrophoretic mobility of phenotype I is the product of two isozymes which, under the conditions of starch gel electrophoresis used, differ insufficiently in mobility to be resolved as two isozymes. This was confirmed by

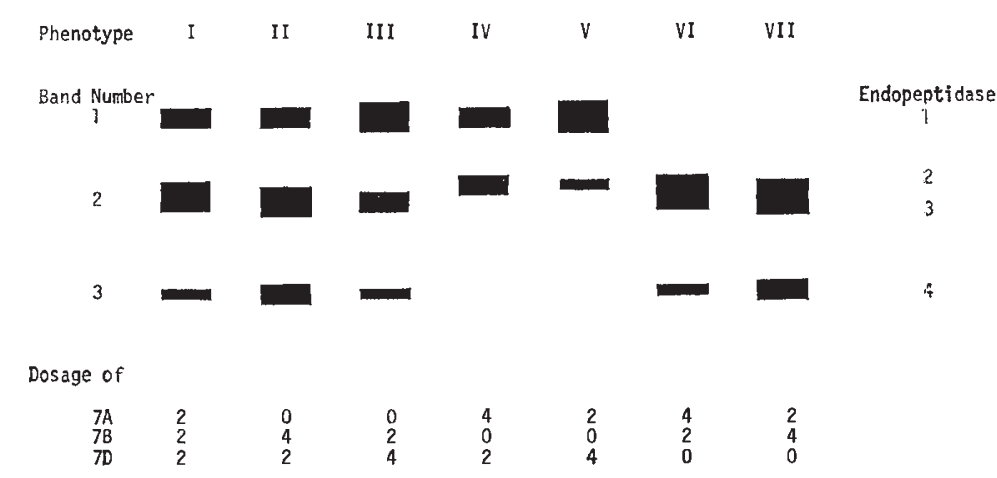

Fig. 5.-Diagram showing the relationships between dosages of the group 7 chromosomes and the EP zymogram phenotypes produced. 
electrophoresis of extracts of "Chinese Spring" in disc acrylamide gels (Hart, 1975). In these gels the relative staining intensities of the EP bands approximate those observed on starch gels but the intermediate zone of activity is resolved into two discrete bands. The zymogram locations of the four EP isozymes are identified by Arabic numerals shown on the right side of fig. 5 .

The zymogram expression of each of the four EP isozymes varies concordantly with the dosage of a specific group 7 chromosome and chromosome arm. EP-1 is not expressed by strains lacking either chromosome 7D (VI and VII, fig. 5) or chromosome arm 7DL, EP-2 is not expressed by strains lacking either 7A (II and III, fig. 5) or 7AL and EP-3 and EP-4 are not expressed by strains lacking either 7B (IV and V, fig. 5) or 7BL. The relative level of expression of the isozymes is increased in strains which are tetrasomic for these respective chromosomes (see also fig. 5). These results indicate that chromosome arms $7 \mathrm{AL}$ and $7 \mathrm{DL}$ carry the structural genes for EP-2 and EP-1, respectively, and 7BL the gene(s) for EP-3 and EP-4.

If 7BL produced but one EP isozyme, a triplicate set of homoeologous EP structural genes located in 7AL, 7BL, and 7DL would clearly be indicated by these findings. However, since $7 \mathrm{BL}$ produces two EP isozymes, the structural gene requirements for the EP isozymes observed may not be satisfied by a triplicate set of genes. 7BL may possess two EP structural genes. Tissue variation has been observed in the expression of EP-4 but not in the expression of the other thrce EP isozymes (Hart and Langston, unpublished). For example, we have not been able to detect the expression of EP-4 in the scutella of 18-hour germinated "Chinese Spring" grains, although the other three EP isozymes express in this tissue and in the other tissues which have been cxamined the same zymogram phenotype as in 7-day-old etiolated shoots. This suggests, although it does not prove, that EP-3 and EP-4 are the products of two structural genes. On this basis we tentatively conclude that the four EP isozymes are the products of four structural genes and that the structural genes for EP-1, EP-2, and EP-3 compose a homoeologous set. We designate these three genes as $E p-D 1$, $E p-A 1$, and $E p-B 1$, respectively, and the structural gene for EP-4 as Ep1. The relationship, is any, of Epl to the members of the triplicate set can only be a matter of speculation at this time. One possibility is that $E p 1$ is a diverged duplicate of $E p-B 1$. A second possibility is that $E p 1$ is the remaining active member of another set of homoeolgous EP genes.

\section{(v) Lipoxygenase}

Five bands of LPX activity have been resolved on disc acrylamide gels in which extracts of coleoptiles of 4-day-old seedlings of euploid " Chinese Spring " have been elcctrophoresed. Analyses of various aneuploid strains have provided evidence that these five bands are the products of six isozymes, two of which have coincident electrophoretic mobilities. The bands occur in two major zones, designated as zone 1 and zone 2 . Zone 1 consists of the two most anodal bands and zone 2 of the three more cathodal bands.

Diagrams of the zone 2 LPX zymogram phenotypes observed in this study are shown in fig. 6 . Each of the chromosome group 5 nulli-tetra types produces a distinctive zone 2 phenotype. However, euploid "Chinese Spring " and all of the other aneuploid strains examined, including ditelo- 
$5 \mathrm{AL}$, ditelo-5BL, and ditelo-5DL, produce the same phenotype, phenotype I. Band $\mathrm{l}$ is not produced by strains nullisomic for chromosome 5A (II and III, fig. 6), band 2 by strains nullisomic for 5B (IV and V, fig. 6) and band 3 by strains nullisomic for 5D (VI and VII, fig. 6). Tetrasomy for each of these chromosomes causes an increase in the relative staining intensities of these respective bands (see also fig. 6).

These results indicate that the three zone 2 LPX isozymes are encoded by genes contained in the long arms of the group 5 chromosomes. We designate the structural genes carried by $5 \mathrm{AL}, 5 \mathrm{BL}$, and $5 \mathrm{DL}$ as $L p x-A 2$, $L p x-B 2$, and $L p x-D 2$, respectively, and the isozymes encoded as LPX-2a (located at the site of band 1), LPX-2b (band 2), and LPX-2c (band 3), respectively.

Diagrams of the zone 1 LPX zymogram phenotypes observed are shown in fig. 7. Euploid " Chinese Spring ", the aneuploid strains that are disomic for each of the group 4 chromosomes, and three of the group 4 ditelosomic

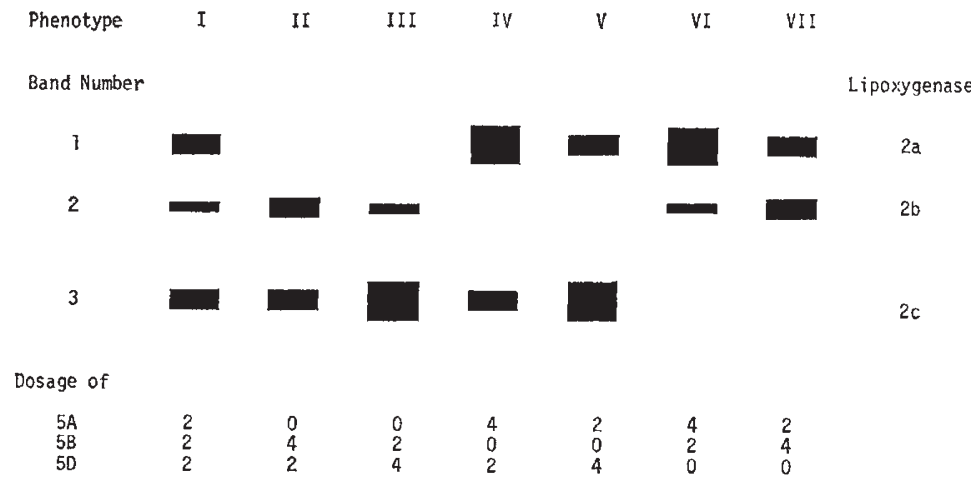

FIG. 6.-Diagram showing the relationships between dosages of the group 5 chromosomes and the zone 2 LPX zymogram phenotypes produced.

strains, namely, ditelo-4A $\alpha,-4 \mathrm{BL},-4 \mathrm{DS}$, produce the same phenotype, phenotype I. However, the group 4 nulli-tetras, ditelo-4DL, and nulli-4A each produce a distinctive phenotype, one which differs from that produced by euploid "Chinese Spring". The simplest hypothesis of genetic control which is consistent with the observed relationships between group 4 chromosome and chromosome arm dosages and the zymogram phenotypes produced is that the chromosome arms $4 \mathrm{~A} \alpha, 4 \mathrm{BL}$, and $4 \mathrm{DS}$ each possess a gene which encodes a LPX isozyme and that the $4 \mathrm{~A} \alpha$ product produces band 1 while the 4BL and 4DS isozymes have coincident electrophoretic mobilities, both contributing to the production of band 2 .

The evidence for this hypothesis with respect to the $4 \mathrm{~A} \alpha$ gene is strong. The expression of band 1 varies strictly in accordance with the dosage of $4 \mathrm{~A}$. The band is not produced by strains nullisomic for 4A (VI, fig. 7) while the relative intensity of the band is increased when $4 \mathrm{~A}$ is tetrasomic (II and IV, fig. 7). The ditelo- $4 \mathrm{~A} \beta$ strain is not available. Linkage of the gene to $4 \mathrm{~A} \alpha$ is indicated by the production of phenotype I by ditelo- $4 \mathrm{~A} \alpha$.

The relative staining intensity of band 2 varies between strains as a function of the dosage of chromosome $4 \mathrm{D}$ to a major extent and, to a lesser 
degree, as a function of the dosage of $4 \mathrm{~B}$ also. Tetrasomy for $4 \mathrm{D}$ causes a major increase in the relative intensity of the band (III, fig. 7). When 4D is absent, band 2 is significantly more intense when there are four doses of $4 \mathrm{~B}$ present (V, fig. 7) than when there arc two doses present (IV, fig. 7). However, when 4D is absent, whether there are two or four doses of $4 \mathrm{~B}$ present, the relative intensity of band 2 is still significantly less than when there are two doses of $4 \mathrm{D}$ present (compare IV and V with I, II, and VI, fig. 7). The relative intensity of band 2 is also greatly reduced when $4 \mathrm{DS}$ is absent (strain ditelo-4DL, VII, fig. 7). The ditelo-4BS strain is not available. The zymogram phenotypes of the ditelo-4BL and -4DS strains do not differ from that of euploid "Chinese Spring".

These results are consistent with the linkage to 4BL and 4DS of two LPX structural genes whose products differ in level of expression but have

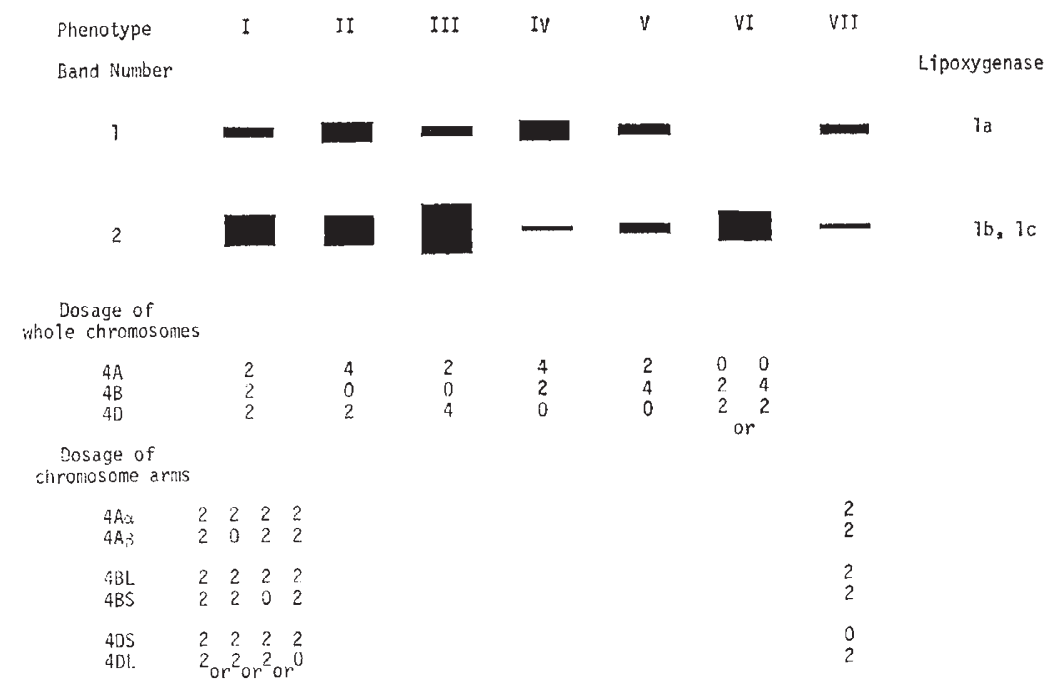

FrG. 7.-Diagram showing the relationships between dosages of the group 4 chromosomes and chronosome arms and the zone 1 LPX zymogram phenotypes produced.

coincident electrophoretic mobilities. To attribute the observed effects of variation in the dosages of 4BL and 4DS solely to non-structural genes which act to regulate the level of expression of the band $2 \mathrm{LPX}(\mathrm{s})$ requires a considerably more complex hypothesis of genetic control. One structural gene located in another chromosome is of course insufficient. The absence of band 2, an effect which would be expected with nullisomy for the chromosome or chromosome arm in which the gene is located, has not been observed. But other observations suggest that the minimum requirement of structural genes for the band $2 \mathrm{LPX}(\mathrm{s})$, if the structural genes are not located in 4B and $4 \mathrm{D}$ as proposed above, is a triplicate set of genes located in homoeologous chromosomes.

For each of the other isozymes analyscd in this study and also for isozymes analysed earlier (Hart, 1970, 1975), evidence has been obtained that structural gene dosage has a direct effect on the level of isozyme expression. Thirty-nine of the 42 compensating nulli-tetra types have been examined 
and in so doing the possible effects on the zone 2 LPX zymogram phenotype of tetrasomy and of nullisomy for each chromosome in the complement (except for nullisomy for 2AS-see MATERIALS and METHODS) have been analysed. No variation in the expression of band 2 has been observed between strains other than the variation which occurs as a consequence of variation in the dosages of $4 \mathrm{~B}$ and $4 \mathrm{D}$. This result could be the consequence of the encoding by each of three genes located in homoeologous chromosomes of LPX's which have coincident electrophoretic mobilities and about the same level of expression. However, this is a complex hypothesis, one that is unwarranted on the basis of the evidence available. It is more reasonable to conclude that $4 \mathrm{BL}$ and $4 \mathrm{DS}$ possess structural genes whose products have coincident electrophoretic mobilities but differ in level of expression.

We accept the hypothesis that the zone 1 LPX isozymes are encoded by a triplicate set of genes located in $4 \mathrm{~A} \alpha, 4 \mathrm{BL}$, and 4DS. We designate the genes as $L p x-A 1, L p x-B 1$, and $L p x-D 1$, respectively, and the isozymes encoded as LPX-Ia (located at the site of band 1), LPX-1b (band 2), and LPX-Ic (also band 2).

Table 1 lists, by chromosome arm location, each gene identified in this study and the subunit or isozyme which the gene encodes.

TABLE 1

Genes identified in this study and the subunits or isozymes which they encode, grouped by chromosome arm locations of the genes

$\begin{array}{ccc}\text { Chromosome arm } & \text { Structural gene } & \text { Subunit or isozyme encoded } \\ \text { 4A } \alpha & A d h-A 1 & \alpha \\ \text { 4A } \alpha & L p x-A 1 & \text { LPX-1a } \\ \text { 4BL } & A d h-B 1 & \beta \\ \text { 4BL } & L p x-B 1 & \text { LPX-1b } \\ \text { 4DS } & A d h-D 1 & \delta \\ \text { 4DS } & L p x-D 1 & \text { LPX-1c } \\ & & \\ \text { 4A } \beta & A c p h 4 & \text { ACPH-4 } \\ \text { 4A } \beta & A c p h 8 & \text { ACPH-8 } \\ \text { 4BS } & A c p h 2 & \text { ACPH-2 } \\ \text { 4BS } & A c p h 3 & \text { ACPH-3 } \\ \text { 4DL } & A c p h 5 & \text { ACPH-5 } \\ \text { 4DL } & A c p h 6 & \text { ACPH-6 } \\ & & \\ \text { 5AL } & L p x-A 2 & \text { LPX-2a } \\ \text { 5BL } & L p x-B 2 & \text { LPX-2b } \\ \text { 5DL } & L p x-D 2 & \text { LPX-2c } \\ & & \\ \text { 6AS } & A m p-A 1 & \text { AMP-1 } \\ \text { 6BS } & A m p-B 1 & \text { AMP-3 } \\ \text { 6DS } & A m p-D 1 & \text { AMP-2 } \\ & & \\ \text { 7AL } & E p-A 1 & \text { EP-2 } \\ \text { 7BL } & E p-B 1 & \text { EP-3 } \\ \text { 7BL } & E p 1 & \text { EP-4 } \\ \text { 7DL } & E p-D 1 & \text { EP-1 }\end{array}$

\section{Discussion}

Zymogram analyses of aneuploid strains have been used in recent years to study the genetic control of a number of isozymes of hexaploid wheat

$39 / 2-$ F 
(Barber et al., 1968, 1969; Hart, 1970, 1975; Nishikawa and Nobuhara, 1971 ; Bergman, 1972; MacDonald and Smith, 1972; May et al., 1973; Cubadda et al., 1975; Kobrehel and Feillet, 1975; Joudrier and Cauderon, 1976). In only a few of these studies has genic control of isozyme production been demonstrated. However, it appears probable that most of the isozyme variation observed between aneuploid strains in these studies is due to variation in dosages of the genes which encode the isozymes. Consequently, by analysis of appropriate strains and by rigorous interpretation of the results obtained, reasonable models for the genic control of the isozymes under study may be constructed and strong evidence for the localisation of structural genes for the isozymes in specific chromosomes and chromosome arms may be obtained (Hart, 1970, 1975).

In this study 25 isozymes have been observed, and the inter-strain zymogram variation of 22 isozymes has been analysed. For each of these 22 isozymes, evidence has been obtained that the observed variation between the aneuploid strains is due to variation in dosage of structural genes. The chromosomal arm locations of 22 structural genes are reported (table 1).

We have identified eight triplicate homoeologous structural gene sets in hexaploid wheat and in addition six ACPH structural genes which are probably homoeologously related (Hart, 1970, 1975; table 1, this paper). The other gene identified, Ep1, may be the remaining active member of a triplicate set or simply a diverged duplicate of Ep-B1 (see Results). Consequently, our results indicate that each of the three members of at least most triplicate structural gene sets remain active in hexaploid wheat. Nei (1969) and Ohta and Kimura (1971) have proposed that many duplicated genes will degenerate and become inert due to the fixation of what would have been, in the absence of duplication, deleterious alleles but which are, given the presence of normally functioning genes, neutral alleles. Our results are not necessarily inconsistent with this proposal for the tetraploid and hexaploid wheats are probably relatively young polyploids.

The potential for gradual functional divergence between duplicate genes and as well for the possible eventual acquisition of a qualitatively new function by one of the genes was recognised long ago by Muller (1935a, 1935b) and Bridges (1935) (see also Muller, 1918 and Bridges, 1919). Since a polyploid is a fixed heterozygote for every structural gene for which homoeoallelic variation exists between duplicate genes carried in the two or more genomes of the species, it is clear that polyploid species have the means to both acquire and maintain a large amount of functional genetic variation.

Our results indicate that there is extensive homoeoallelic variation in structural genes in hexaploid wheat. The six presumably homoeologous ACPH genes all differ from one another and among the eight triplicate sets of genes identified (a total of 24 genes), only four indistinguishable pairs of genes have been found, namely $A d h-B 1$ and $A d h-D 1$ (Hart, 1970) and one pair of genes among each of the threc glutamate oxaloacetate transaminase (GOT) sets (Hart, 1975). Presumably some of this variation arose in the progenitor diploid species (and thus was present in the original polyploid wheats) and some in the polyploids subsequent to their origin. A quantitative assessment for these genes of the amount of divergence which has occurred subsequent to the formation of the polyploid wheats has not been made. Evidence has been obtained that $A d h-A 1$ diverged from $A d h-B 1$ and $A d h-D 1$ 
subsequent to the origin of tetraploid wheat. Adh-B1 and $A d h-D 1$ of the polyploids are indistinguishable from each other and from the $\mathrm{ADH}$ structural gene which is characteristic of the diploid species of Triticum, including the A genome diploid. Adh-A1 of the polyploid wheats (except T. timopheevi) differs from these genes (Hart, 1971). Divergence has also occurred between the Acph4 genes of tetraploid and hexaploid wheat (Torres and Hart, 1976). Further studies are required. Nevertheless, it is clear that the pattern of homoeoallelic variation detected to date in this and other studies (e.g., Hart, 1970, 1975; Nishikawa and Nobuhara, 1971; May et al., 1973) is that which is to be expected in a young polyploid in which divergence between duplicate genes is occurring over a period of evolutionary time.

Our findings and conclusions differ markedly from those of Brewer et al. (1969). They detected intergenomic variation for only one enzyme system, alkaline phosphatase, among 12 examined in a study of the zymogram phenotypes produced by 38 compensating nulli-tetra strains. In an earlier study (Sing and Brewer, 1969), involving eight of these enzymes, they had detected considerable variation between contemporary diploid species. On the basis of these findings they suggested that, with respect to genes involved in isozyme production, a convergence in the genetic content of the three genomes contained in hexaploid wheat occurred subsequent to the origin of the polyploid wheats as a consequence of strong selection for identical gene content in the three genomes. Further, they suggested that from the point where identity of gene content of the three genomes evolved, selection has operated to preserve this identity. This hypothesis no longer seems tenable, since extensive intergenomic variation between structural genes for isozymes has been demonstrated.

It should be noted that there may well be identity of structural and regulatory genes between the three genomes of hexaploid wheat for some enzyme systems, including some of those studied by Brewer et al. (1969). However, such identity is difficult to prove and surely cannot be concluded for a given system until so indicated by the results of a careful study of the developmental and tissue specificities of expression and the genetic control of each of the isozymes which compose the system. Among the enzyme systems examined by Brewer et al. (1969), intergenomic variation has been demonstrated for esterases (Barber et al., 1968; Bergman, 1972; May et al., 1973; Cubadda et al., 1975) malate dehydrogenases (Bergman, 1972) and aminopeptidases (this paper). Brewer et al. (1969) detected intergenomic variation for alkaline phosphatases but not acid phosphatases. We have concluded that the enzymes which they designated as alkaline phosphatases are rather acid phosphatases. We have been unable to detect alkaline phosphatases in wheat (unpublished).

Fincham (1969) and Barber (1970) have proposed that new and advantageous oligomeric enzymes may be produced in polyploids by association of polypeptides encoded by differing members of duplicate structural gene sets. Four of the enzyme systems we have studied, namely, the ADH and the three GOT systems, are composed of oligomeric enzymes. The species is a fixed heterozygote for genic variation which produces a heterooligomeric enzyme in each of these systems. No evidence has been obtained that the other enzymes studied are oligomers. It is of interest to note that the products of the triplicate gene sets which encode the oligomeric enzymes are less diverged from each other in those properties observable with the 
zymogram technique than are the products of the gene sets which cncode the other enzymes. The only observed difference among the former is that the product of one member of each set differs from the other two in electrophoretic mobility. The evidence available indicates that the three members of each gene set produce approximately the same quantity of subunit, that the subunits randomly associate to produce the active dimcric molecules, and that each of the types produced is equally active. However, the products of the members of the latter groups, exccpting LPX-1b and LPX-1c, all differ from one another in electrophoretic mobility and most differ in level of expression.

The extent to which the homoeoallelic variation in structural genes which has been detected is of functional significance is difficult to assess. The problem does not differ fundamentally from that of determining the functional significancc of the extensive allozyme variation which has been detected in diploid species (see Lewontin, 1974, for review). However, careful studies of the developmental, tissue and subcellular specificities and of the biochemical parameters of the isozymes of polyploids and their progenitor species, such as have been conducted with animal lactate dehydrogenases (Markert, Shaklee, and Whitt, 1975), should allow reasonable inferences to be drawn as to the significance of the evolutionary changes which have occurred.

Acknowledgments.-We are very grateful to Dr E. R. Sears for supplying seed stocks of the strains used in this study. G. E. H. is indebted to the personnel of the Plant Breeding Institute, Cambridge, England, for the facilities and the congenial atmosphere provided while this paper was being written.

This paper is Technical Article No. 13122 of the Texas Agricultural Experiment Station.

\section{REFERENCES}

BARBER, H. N. 1970. Hybridization and the evolution of plants. Taxon, 19, 154-160.

BARBER, I1. N., DRTSCOLl, C. J., LONG, P. M., AND VICKERY, R. s. 1968. Protein genetics of wheat and homoeologous relationships of chromosomes. Nature, 218, 450-452.

BARBER, H. N., DRISCOLL, C. J., LONG, P. M., AND VIGKERY, R. S. 1969. Gene similarity of the Triticinae and the study of segmental interchanges. Nature, 222, 897-898.

BERGMAN, J. W. 1972. Chromosome locations of genes controlling esterase and malate dehydrogenase isozymes in Triticum. Ph.D. dissertation, North Dakota State University, U.S.A.

BREWER, G. J., SING, G. F., AND SFARS, E. R. 1969. Studies of isozyme patterns in nullisomictetrasomic combinations of hexaploid wheat. Proc. natl. Acad. Sci. U.S.A., 64, 12241229.

BRIDGES, c. B. 1919. Duplication. Anat. Rec., 15, 357-358.

BRIDGES, C. B. 1935. Salivary chromosome maps with a key to the banding of the chromosomes of Drosophila melanogaster. 7. Hered., 26, 60-64.

CARLson, P. s. 1972. Locating genetic loci with aneuploids. Molec. gen. Genet., 114, 272280.

CUBADDA, R., BOZZINI, A., AND QUATrRUCCI, E. 1975. Genetic control of esterases in common wheat. Theoret. Appl. Genet., 4.5, 290-293.

Fincinam, J. R. S. 1969. Hybrid proteins and enzyme evolution. Proc. 11th Inter. Botanical Congr., 60.

Guss, P. L., MACKo, v., RICHARdSON, T., AND STAHMANN, M. A. 1968. Lipoxidase in early growth of wheat. Plant Cell Physiol., 9, 415-422.

IALDANE, J. B. S. 1932. The Causes of Evolution. Longmans, Green, and Co., London.

haldane, J. B. S. 1933. The part played by recurrent mutation in evolution. Am. Nat., $67,5-19$.

Harland, s. C. 1934. The genetics of colton. Part XI. Further experiments on the inheritance of chlorophyll deficiency in New World cottons. 7. Genet., 29, 181-195. Harland, s. c. 1936. The genetical conception of the species. Biol. Rev., 11, 88-112. 
HART, G. E. 1970. Evidence for triplicate genes for alcohol dehydrogenase in hexaploid wheat. Proc. natl. Acad. Sci. U.S.A., 66, $1136-1141$.

HART, G. E. 1971. Evolution of alcohol dehydrogenase isozymes in Triticum. Isozyme Bulletin, 4, 15.

hart, G. E. 1973. Homoeologous gene evolution in hexaploid wheat. Proc. 4th Inter. Wheat Genet. Symp., 805-810.

HART, G. E. 1975. Glutamate oxaloacetate transaminase isozymes of Triticum: Evidence for multiple systems of triplicate structural genes. In Isozymes, ed. C. L. Markert, vol. 3, pp. 637-657. Academic Press, N.Y.

JOUDRIER, M. P., AND CAUDERON, Y. 1976. Localisation chromosomique de génes contrôlant la synthèse de certain constituants $\beta$ amylasique du grain de Blé tendre. Comptes Rendus Ac. Sc. Paris, D, 282, 115-118.

KOBREHEL, K., AND FEILLET, P. 1975. Identification of genomes and chromosomes involved in peroxidase synthesis of wheat seeds. Can. F. Bot., 53, 2336-2344.

LeWontin, R. C. 1974. The Genetical Basis of Evolutionary Change. Columbia University Press, New York.

MACDONALD, T., AND SMITH, H. H. 1972. Variation associated with an Aegilops umbellulata chromosome segment incorporated in wheat. II. Peroxidase and leucine aminopeptidase isozymes. Genetics, 72, 77-86.

MCFADDEN, E. S., AND SEARS, E. R. 1946. The origin of Triticum spelta and its free-threshing hexaploid relatives. F. Hered., 37, 81-89, 107-116.

maintosh, R. A. 1973. A catalogue of gene symbols for wheat. Proc. 4th Inter. Wheat Genet. Symp., 893-937.

Markert, C. 1.., shaklee, J. P., AND Whitt, G. s. 1975. Evolution of a gene. Science, 189, 102-114.

MAY, C. E., VICKERY, R. S., AND DRISCOLL, C. J. 1973. Gene control in hexaploid wheat. Proc. 4th Inter. Wheat Genet. Symp., 843-849.

MULLER, H. J. 1918. Genetic variability, twin hybrids, and constant hybrids, in a case of balanced lethals. Genetics, 3, 422-499.

MULLER, H. J. 1935a. The origination of chromatin deficiencies as minute deletions subject to insertion elsewhere. Genetica, 17, 237-252.

MULLER, H. J. 1935b. A viable two-gene deficiency phenotypically resembling the corresponding hypomorphic mutations. 7. Hered., 26, 469-478.

NEI, M. 1969. Gene duplication and nucleotide substitution in evolution. Nature, 221, $40-42$.

NishikaWA, K., AND Nobuhara, M. 1971. Genetic studies of $\alpha$-amylase isozymes in wheat, I. Location of genes and variation in tetra- and hexaploid wheat. 7ap. 7. Genet., 46, 345-353.

OHTA, T., AND кімURA, м. 1971. Functional organization of genetic material as a product of molecular evolution. Nature, 233, 118-119.

RiLeY, R. 1965. Cytogenetics and the evolution of wheat. In Essays on Crop Plant Evolution, ed. Sir J. Hutchinson, pp. 103-122. Cambridge University Press.

SEARs, E. R. 1954. The aneuploids of common wheat. Missouri Agric. Exp. Sta. Res. Bull., No. 572,58 pp.

SEARS, E. R. 1966a. Nullisomic-tetrasomic combinations in hexaploid wheat. In Chromosome Manipulations and Plant Genetics, eds. R. Riley and K. R. Lewis, pp. 29-45. Oliver and Boyd, London.

SEARS, E. R. 1966b. Chromosome mapping with the aid of telocentrics. Proc. 2nd Inter. Wheat Genet. Symp., Hereditas Suppl. 2, 370-381.

SING, C. F., AND BREWER, G. J. 1969. Isozymes of a polyploid series of wheat. Genetics, 61, 391-398.

TANG, K. S., AND HART, G. E. 1975. Use of isozymes as chromosome markers in wheat-rye addition lines and in triticale. Genet. Res. Camb., 26, 187-201.

TORRES, M. A., AND HART, G. E. 1976. Developmental specificity and evolution of the acid phosphatase isozymes of Triticum aestivum and its progenitor species. Biochem. Genet., 14, 595-609. 